\title{
The Need for Shift in Approach to Suicide Prevention in Australia
}

\author{
Shravankumar Guntuku \\ Men's Health Information and Resource Centre, Western Sydney University, Sydney, Australia \\ Email: s.guntuku@westernsydney.edu.au
}

How to cite this paper: Guntuku, S. (2020). The Need for Shift in Approach to Suicide Prevention in Australia. Open Journal of Social Sciences, 8, 150-157. https://doi.org/10.4236/jss.2020.88013

Received: July 25, 2020

Accepted: August 17, 2020

Published: August 20, 2020

Copyright $\odot 2020$ by author(s) and Scientific Research Publishing Inc. This work is licensed under the Creative Commons Attribution International License (CC BY 4.0).

http://creativecommons.org/licenses/by/4.0/

\begin{abstract}
This article reviews the current approach to suicide prevention in Australia, which is focused on medical model and argues the need for shifting the approach to social model. The new situational approach should focus on social determinants and consider the risk factors such as aboriginality, unemployment, financial distress and relationship breakdown alongside metal illness. The new approach has been successful in many local interventions. For example, The Shed in Mt Druitt, Sydney is partnering with twenty-eight local organisations to address the social determinants to reduce the suicide rate.
\end{abstract}

\section{Keywords}

Social Determinants of Suicide, Suicide Prevention, Men's Health, Situational Approach

\section{Background}

Despite the enormous increase in funding of mental health service delivery, suicide rates in Australia are still at the same level and have not reduced in the past two decades (Bastiampillai et al., 2020). It is a serious public health issue in many countries, amounting up to $1.3 \%$ of the global burden of disease (Ashfield et al., 2017). World Health Organisation (WHO) (2011) reported that internationally suicide is the cause for almost one million deaths. Alone in Australia, over 2.2 million people aged between 16 - 85 expressed suicide ideation (Department of Health and Ageing, 2013). Suicide also has an economic cost to the families, community and the government. KPMG (2019) estimated that economic cost of suicide in Australia is over fifteen billion per year in various forms, such as loss of productivity, medical treatment for non-fatal suicide attempts and other homicides. This evidence clearly challenges the current approaches in suicide pre- 
vention and shows the gaps in traditional interventions. This paper reviews the current evidence on the critical risk factors of suicide and proposes an alternative approach, which focuses on Social determinants such as gender, economic status, aboriginality and family or relationship conflicts.

This is an educational research using both descriptive and associational types of methods to analyse existing content and evidence of the current approaches in suicide prevention sector. This research also compares the existing evidence with more holistic approach to focus on Social determinants or underlying factors in the future.

Suicide is often looked at as a mental health problem, but when studied in depth, the real causes are often the social determinants, such as unemployment, childhood trauma, experience of sexual abuse, chronic pain, relationship breakdown, loss of farm \& social isolation (in rural areas), stressful life events, loss of a loved one and intergenerational trauma in Indigenous families (Ridani et al., 2016; Macdonald et al., 2014). ABS (2019) also reported that, depression is the main cause for suicide ideation and depression is linked to various social determinants. To be precise, relationship separation is one of the major contributors to the depression amounting up to 28.3 per cent, followed by financial problems at 17 per cent and unemployment and pending legal matters amounts up to 10.5 per cent (ABS, 2019). Many studies, such as Reeves et al. (2015) and Milner et al. (2019), reported that long period of financial distress and unemployment is one of the biggest causes of suicidal ideation in Australia.

Unemployment/under employment can be major contributing factor to the depression as it determines the social and economic status of individuals in any society (Smith, 1985). As Norström \& Grönqvist, (2015) stated the large number of suicides reported during the Great Recession and World War II are the evidence to link the unemployment and increased number of suicides across the globe. Furthermore, loss of employment can have adverse effects on mental health of any individuals as it breaks the routine, vanishes the social relationships and adds the financial distress (Norström \& Grönqvist, 2015). Gunnell \& Chang (2016); Iglesias-García et al. (2016) also suggest that poverty and financial anxiety are the major contributors to the depression which can lead to suicidal ideation when it is not addressed. These studies suggest the importance of approaching the suicide as a systemic issue at the population level by addressing underlying issues such as unemployment and financial distress.

In 2018, more than 3000 deaths have been recorded in Australia as intentional self-harm (suicide), which is 8.3 deaths each day (Australian Bureau of Statistics, 2018). Although the rate of suicide attempts is higher for women, men are three time more likely to complete the suicide, that is six out of eight deaths (Ridani et al., 2016). Suicide is the second largest cause of deaths among Australian males, after prostate cancer (amounting up to 16 per cent) more than the road accidents and homicides (ABS, 2019). The black dog institute also reported that, Aboriginal and Torres-strait Islander men and boys aged between 15 to 25 are at 
higher risk among Australians, along with men living in remote and rural areas. In 2018 alone suicides among Aboriginal and Torres-straight Islanders were four times higher than the non-aboriginals (ABS, 2019). These alarming numbers of male suicides require the gendered approach in suicide prevention (Baker, 2015).

The New South Wales (NSW) Health Ministry has acknowledged the significance of social determinants of health $(\mathrm{SDOH})$ in addressing the male health issues as early as 1999, by initiating a study called "Moving Forward in Men's Health". The study has recommended that the SDOH should be the priority for any future health interventions for men (Baker, 2015). However, the National Mental Health Policy 2008, National Male Health Policy 2010 and the recent National Male Health Strategy 2020 have failed to address the suicides of males as key priority action area to work on (Australian Men's Health Forum (AMHF), 2020).

Although, international evidence shows that the accessibility of professional help reduces the rate of suicide (Levine \& Sher, 2020). The availability of psychiatrists and social workers, who looks at the sensitive issues such as suicide in remote and rural areas of Australia is questionable (Macdonald et al., 2014). Whereas, the men living in remote and rural Australia are highly represented in both mental health issues and suicides attempts (Ridani et al., 2016). More often, suicide is not looked with a gender lens even though 80 per cent of Australian suicide deaths are by men, which needs a critical attention by the practitioners, particularly the social workers working with men in the community. The recent evidence shows that the need for non-mental health social workers, who encounter the clients with suicide in Australia has grown in the past decade (Osteen et al., 2014). The real challenge is that the practitioners do not have adequate skills to identify the risk factors contributing to suicide ideation as the current suicide prevention activity is highly focused on either pathological diagnosis or crisis helplines (Macdonald et al., 2014). There is limited evidence that, the suicide prevention programs focused only on mental health services are successful to reduce the suicide rates (McPhedran \& De Leo, 2013). McPhedran \& De Leo (2013), also reported that 40 per cent rural people had visited a mental health professional within 3 months before taking their own life, which suggests the gap in identifying the risk and need for a change in approach. the United Nations Special Rapporteur on the right to Health, Dr. Dainius Pưras (United Nations, 2017) also called for a shift in approach in both funding and implementation of suicide prevention across the globe. I can only be achieved reducing the focus on mental health treatment plans and by strengthening the skills of practitioners to identify and work with social determinants.

\section{Alternative Approach}

Ms Christine Morgan, National Suicide Prevention Advisor to Prime Minister says "We need to actively seek to understand and reduce the factors that contri- 
bute to despair and suicidal thoughts. This means looking towards the social determinants of suicide, and effective policy shifts as well as interventions that can reduce their impacts" (Morgan, 2019). Social work practitioners with holistic approach have a significant role play in suicide prevention and postvention. It is important that the need to build the evidence base though research to inform these practices. However, according to Joe and Niedermeir (2008), the research on suicide prevention with a social work approach is facing a scarcity across the globe. It is important to note the National Suicide Prevention Strategy 2012 and National Mental Health Plan 2009-14 provided guidelines to develop targeted activities but failed to acknowledge the social determinants.

However, the recent developments have been positive towards zero suicide initiative, as the New South Wales (NSW) government and Primary Health Networks (PHN) are starting to fund the alternative approaches such as, gate keepers training and "The Shed in Mt Druitt", to prevent suicide. Several researchers have stated that the gate keeper training is one of the most effective interventions in prevention of suicides as they play a key role in identifying the risk factors and prevent the crisis to escalate further (Levine \& Sher, 2020). In the United States the community gatekeeper training initiated by the social work agencies have shown great results in preventing the suicide risk in vulnerable communities (Levine \& Sher, 2020). These studies also recommended that the similar model should be used to build the skills and diagnostic abilities of non-mental health social workers in the field of suicide prevention across the globe (Levine \& Sher, 2020).

The acknowledgement of gender dynamic is very significant in the prevention of suicide globally and particularly in Australia. As the statistics from ABS (2019) and Baker (2018) states, males are 4 times more at the risk of completing a suicide than females due to various factors such as, their help seeking behavior and unavailability of male-friendly services. The reports in the media about "men do not talk or seek for help" mask the real need to have a male friendly approach to the service delivery (Ashfield et al., 2017). The critics of the National Male Health Policy 2010, suggest that suicide should be the priority action area taking the risk factors into consideration and the practitioners should be informed with the knowledge of gender difference if they want to succeed (Mendoza \& Rosenberg, 2010). Sadly, this is one of the reasons that the suicide mortality rate in the last two decades has risen alarmingly rather than diminishing, despite large amounts of public funds in the service delivery (Ashfield et al., 2017).

The Shed in Mt Druitt (A drop in center for people in crisis), supports men and women who consider themselves at risk of serious stress and suicide, generally on account of cumulative stress often due to disadvantaged situations. Most of the visitors at The Shed are of Aboriginal and Torres Strait Islander origin since these are often most at risk (Macdonald et al., 2014). The Shed partners with twenty-eight organisations such as legal aid, Uniting, NSW Health and so- 
cial workers from University of Sydney, which has shown a great positive result in reduction of suicides in the local area (Macdonald \& Welsh, 2012). This is a classic example of how the suicide prevention approach in multi-disciplinary setting can reduce suicide, by working collaboratively with multiple organisations. It is evident that structural barriers in formal setting can limit the access of indigenous people from seeking help (Jabour, 2017). This approach by The Shed is very informal, where they sit around the fire and chat with professionals about their life events enabling the practitioners to identify the risk factors and refer them to personlised, local and culturally appropriate services at no cost (Panagiotaros et al., 2019). The Shed has many success stories such as, Paul who got his children back from the foster care which stopped him from killing himself and now found himself an employment to look up for (Panagiotaros et al., 2019). This approach of suicide prevention is cost effective, informal, successful and most importantly replicable with the existing funding arrangements by strengthening the social work practices to follow alternative approaches rather than focusing on only traditional practices.

There are many reports emerging that due to pandemic COVID-19, millions of people across the globe will lose their employment and will be at the risk of experiencing suicidal ideation (Workplace Gender Equality Agency statistics (WGEA), 2020). Global Action for Men's Health (Baker et al., 2020) also reported that the suicide rate could increase dramatically with the impact of this sudden shock to economy and Australian males who work in male dominated industries such as, manufacturing, transport, construction and mining have become more vulnerable. This requires a shift in looking at the suicide prevention in Australia through the lens of unemployment and skill building rather than medical illness. This alternative approach will help in not repeating the suicide rates as much as at the time of great depression.

The current approach is clearly ineffective and is dominated by a number of major deficits that are systemic, pervasive, and deeply entrenched. These deficits include; poor targeting of some of the groups with the highest rates and the highest numbers of suicide deaths; the unnecessary and potentially harmful medicalisation and pathological categorisation of human distress and disregard for the situational and dimensional nature of human experience.

This new approach acknowledges the predominant association of situational distress, rather than mental illness, with suicide (though in some cases the two are linked) and is principally informed by and responds to risk factors of a broad spectrum of difficult human experiences across the life span. This approach is also mindful of and wherever possible seeks to address contextual, systemic, and socio-cultural risk and protective factors and determinants: the real world of individuals' lived experience. A public health approach emphasises an "up-stream" perspective: one that focuses on risk and protective factors in order to prevent the kinds of intense or prolonged distress that can escalate into suicidality, rather than a "downstream" approach, which focuses on dealing with crises and their aftermath. 


\section{Conclusion}

In conclusion, suicide prevention is a very significant issue. Particularly, in Australia, where men represent the 80 per cent of suicide deaths, there is a real need for shift in approach. The funding allocation and service delivery should be prioratised to address risk factors such as unemployment, pending legal matters, relationship breakdown and targeted interventions towards Aboriginal men and women. Looking at the suicide prevention through a gender lens with the social determinants approach is the only way forward to achieve the zero suicide targets and to see the value for the large amounts of public funding spent on suicide prevention activities both at the federal level and by the individual states. Local interventions such as The Shed in Mt Druitt, Sydney, based on the social determinants are successfully reducing the rates of suicide among many communities, which needs boost in funding and promoted as best models of suicide prevention at early stages of distress.

\section{Conflicts of Interest}

The author declares no conflicts of interest regarding the publication of this paper.

\section{References}

Ashfield, J., Macdonald, J., \& Smith, A. (2017). A “Situational Approach" to Suicide Prevention (p. 1). https://doi.org/10.25155/2017/150417

Australian Bureau of Statistics ABS (2018). 3303.0-Causes of Death, Australia, 2017. https://www.abs.gov.au/ausstats/abs@.nsf/Lookup/by\%20Subject/3303.0 2017 Main\% 20Features Intentional\%20self-harm,\%20key\%20characteristics $\sim 3$

Australian Bureau of Statistics ABS (2019). 3303.0-Causes of Death, Australia, 2018. https://www.abs.gov.au/ausstats/abs@.nsf/0/47E19CA15036B04BCA2577570014668B? Opendocument

Australian Men's Health Forum (2020). National Strategies Failing to Stop Male Suicide, Health Experts Say.

https://www.amhf.org.au/national_strategies_failing_to_stop_male_suicide_health_exp erts_say

Baker, P. (2015). National Men's Health Policies: Can They Help? Trends in Urology \& Men's Health, 6, 24-26. https://doi.org/10.1002/tre.493

Baker, P. (2018). Men's Health: Time for a New Approach. Physical Therapy Reviews, 23, 144-150. https://doi.org/10.1080/10833196.2018.1452562

Baker, P., White, A., \& Morgan, R. (2020). Men's health: COVID-19 Pandemic Highlights Need for Overdue Policy Action. The Lancet, 395, 1886-1888.

Bastiampillai, T., Allison, S., Looi, J. C., Tavella, A., \& Agis, U. (2020). Why Are Australia's Suicide Rates Returning to the Hundred-Year Average, despite Suicide Prevention Initiatives? Reframing the Problem from the Perspective of Durkheim. Australian \& New Zealand Journal of Psychiatry, 54, 12-14. https://doi.org/10.1177/0004867419872815

Department of Health and Ageing (2013). National Mental Health Report 2013: Tracking Progress of Mental Health Reform in Australia 1993-2011. 
Gunnell, D., \& Chang, S. S. (2016). Economic Recession, Unemployment, and Suicide. In R. C. O'Connor, \& J. Pirkis (Eds.), The International Handbook of Suicide Prevention (pp. 284-300). Hoboken, NJ: Wiley. https://doi.org/10.1002/9781118903223.ch16

Iglesias-García, C. I., Saiz, P. A., Bousoño, M., Buron, P., Lasheras, F. S., Corcoran, P. et al. (2016). Possible Delayed Effect of Unemployment on Suicide. European Psychiatry, 33, S327.

Jabour, B. (2017). The Shed: I Keep Coming Because There Are People Who Listen. https://www.theguardian.com/australia-news/2017/feb/22/the-shed-i-keep-coming-bec ause-there-are-people-who-listen

Joe, S., \& Niedermeier, D. (2008). Preventing Suicide: A Neglected Social Work Research Agenda. British Journal of Social Work, 38, 507-530. https://doi.org/10.1093/bjsw/bcl353

KPMG (2019). Turning Points: Imagine a World without Suicide. https://home.kpmg/au/en/home/insights/2019/09/suicide-prevention-imagine-worldwithout-suicide.html

Levine, J., \& Sher, L. (2020). How to Increase the Role of Social Workers in Suicide Preventive Interventions. Acta Neuropsychiatrica, 32, 186-195. https://doi.org/10.1017/neu.2020.11

Macdonald, J. J., \& Welsh, R. (2012). The Shed in Mt Druitt: Addressing the Social Determinants of Male Health and Illness. Sydney: Western Sydney University.

Macdonald, J. J., Sliwka, G., Smith, A., \& Trezise, E. (2014). Pathways to Despair: A Study of Male Suicide (Aged 25-44). Public Health Research, 4,: 62-70.

McPhedran, S., \& De Leo, D. (2013). Miseries Suffered, Unvoiced, Unknown? Communication of Suicidal Intent by Men in "Rural" Queensland, Australia. Suicide and Life-Threatening Behavior, 43, 589-597. https://doi.org/10.1111/sltb.12041

Mendoza, J., \& Rosenberg, S. (2010). Suicide and Suicide Prevention in Australia: Breaking the Silence. Lifeline Australia and Suicide Prevention Australia.

Milner, A., Aitken, Z., Law, P. C. F., LaMontagne, A. D., Mann, C., Cooper, T., \& Witt, K. (2019). The Relationship between an Electronic Mental Health Stigma Campaign and Suicidal Thoughts and Behaviours: A Two-Arm Randomized Controlled Trial in the Australian Construction Industry. Health Promotion International, 35, 478-485. https://doi.org/10.1093/heapro/daz034

Morgan, C. (2019). A Message from the National Suicide Prevention Adviser. The Department of Health.

https://www1.health.gov.au/internet/main/publishing.nsf/Content/mental-national-sui cide-prevention-adviser

Norström, T., \& Grönqvist, H. (2015). The Great Recession, Unemployment and Suicide. Journal of Epidemiology and Community Health, 69, 110-116.

Osteen, P. J., Jacobson, J. M., \& Sharpe, T. L. (2014). Suicide Prevention in Social Work Education: How Prepared Are Social Work Students? Journal of Social Work Education, 50, 349-364. https://doi.org/10.1080/10437797.2014.885272

Panagiotaros, C., Hall, N., \& Macdonald, J. J. (2019). In Our Words: Stories from the Shed Mount Druitt. Western Sydney University. http://www.mengage.org.au/images/The_Shed_Stories_1MB.pdf

Reeves, A., McKee, M., Gunnell, D., Chang, S. S., Basu, S., Barr, B., \& Stuckler, D. (2015). Economic Shocks, Resilience, and Male Suicides in the Great Recession: Cross-National Analysis of 20 EU Countries. The European Journal of Public Health, 25, 404-409. https://doi.org/10.1093/eurpub/cku168 
Ridani, R., Torok, M., Shand, F., Holland, C., Murray, S., Borrowdale, K., Sheedy, M., Crowe, J., Cockayne, N., \& Christensen, H. (2016). An Evidence-Based Systems Approach to Suicide Prevention: Guidance on Planning, Commissioning, and Monitoring. Sydney: Black Dog Institute.

Smith, R. (1985). Occupationless Health. "I couldn't Stand It Any More": Suicide and Unemployment. British Medical Journal (Clinical Research Ed.), 291, 1563.

https://doi.org/10.1136/bmj.291.6508.1563

United Nations (2017). World Needs "Revolution" in Mental Health Care-UN Rights Expert.

https://www.ohchr.org/EN/NewsEvents/Pages/DisplayNews.aspx?NewsID=21689

Workplace Gender Equality Agency (2020). Gendered Impact of COVID-19. https://www.wgea.gov.au/topics/gendered-impact-of-covid-19

World Health Organization (2011). Suicide Rates per 100,000 by Country, Year and Sex. Geneva: WHO. 